\title{
Research on the Structural Mutation of Carbon Emission Allowance Trading Price of China
}

\author{
Ruitong Xia ${ }^{1,2}$ \\ ${ }^{1}$ Postdoctoral Workstation of China Construction Bank, Beijing, China \\ ${ }^{2}$ Postdoctoral Research Station of Tsinghua University, Beijing, China \\ Email: xiaruitong3620@126.com
}

How to cite this paper: Xia, R. T. (2021). Research on the Structural Mutation of Carbon Emission Allowance Trading Price of China. Open Journal of Business and Management, 9, 2487-2496.

https://doi.org/10.4236/ojbm.2021.95135

Received: September 7, 2021

Accepted: September 21, 2021

Published: September 24, 2021

Copyright (c) 2021 by author(s) and Scientific Research Publishing Inc. This work is licensed under the Creative Commons Attribution International License (CC BY 4.0).

http://creativecommons.org/licenses/by/4.0/

\begin{abstract}
This paper conducts theoretical and empirical research on the structural mutation of China's carbon emission allowance trading price. Firstly, it analyzes the possibility of price mutation from the perspective of market mechanism through theoretical analysis. Secondly, the Bai-Perron Multiple Breakpoint Test method is used to test the autoregressive model of the carbon valence sequence. It is found that the carbon emission price series of each pilot have multiple structural mutations, and the breakpoints often occur around the annual compliance date. It is believed that the compliance requirement is the direct internal factor that causes the sudden change in the carbon emission price structure. Combined with the observation of market transaction characteristics and the direction of price sudden changes, the analysis of the deeper internal causes of price sudden changes in the market lies in the poor ability of enterprises to actively manage quotas, low market transaction activity, and excessive total supply of quotas. Based on the problems and reasons reflected by the empirical test results, this paper finally puts forward three rationalization suggestions for the improvement of the carbon emission allowance trading market.
\end{abstract}

\section{Keywords}

Carbon Finance, Carbon Emission Allowance Trading, Price Mutation, Bai-Perron Structural Mutation Points Test

\section{Introduction}

As a developing country with the largest emissions of greenhouse gases, China has formally made a commitment to the world that the carbon emissions will peak in 2030 and realize carbon neutral in 2060, and actively deploy a "dual carbon" target action plan. The carbon emission allowance trading is one of the 
important paths for the market mechanism to promote greenhouse gas emissions reduction. Since 2013, China has successively established seven carbon emission allowance trading pilots, and a unified national carbon emission allowance trading market has been officially launched on July 16, 2021. In order to better play the role of the market mechanism in reducing emissions, activating market liquidity and increasing the investment value of carbon emission allowance are the focus of future development. More institutions and individual investors may participate in carbon emission market transactions. The transaction price of secondary market will also have more reference value. Therefore, research on the fluctuations of carbon emission allowance trading price in the pilot market will provide a theoretical basis for further exploration of practical issues such as market pricing, investment decision-making, and price fluctuation management, and provide reference suggestions for the improvement of market mechanism of the national carbon emission allowance trading.

The innovation of this paper is to capture the characteristics of structural mutations in carbon emission allowance trading prices from a unique perspective, and to analyze the causes of price changes in depth at the level of market mechanisms. In terms of structural arrangement, the article includes four parts: literature review, theoretical research, empirical testing, conclusions and suggestions.

\section{Literature Review}

Due to the long running time of the EU carbon emission allowance trading market and the relatively complete market and price mechanism, scholars have been paying attention to the factors that affect the EU carbon emission allowance trading price very early. According to existing research results, the factors affecting the price of carbon emissions can be summarized as energy prices, extreme weather, economic factors, policy mechanisms, information disclosure, etc. Among them, energy prices and temperature changes are the two factors that are generally believed to have the greatest impact on carbon emission prices: Keppler \& Bataller (2010) based on the long-term abatement cost theory and short-term rent-seeking theory, respectively, to the EU carbon emission market in the first stage and Analysis of the transaction price in the second stage revealed that the carbon emission price in the first stage is guided by long-term emission reduction costs. The increase in coal and natural gas prices will increase the emission reduction costs of enterprises, thereby significantly pushing up the price of carbon emission rights. In the second stage, carbon emission prices are more driven by electricity prices, and short-term rent-seeking is obvious. Nwani and Chinazaekpere (2017) believe that the increase in crude oil prices means an increase in demand for energy consumption. In order to produce more oil, companies will inevitably increase carbon dioxide emissions, and the demand for carbon emission rights is higher, which makes the price of carbon emission allowance higher. Hintermann (2012) used the EU market's 
first-stage carbon emission allowance trading data to conduct research and found that weather changes are one of the driving factors of carbon emission prices, which makes carbon emission prices show seasonal characteristics. In addition to energy prices and weather factors, the impact of macroeconomic factors has also been verified by many scholars. Different scholars have different choices of macroeconomic factors: Aatola, Ollikainen, \& Toppinen (2013) used stock indexes as indicators to describe the macroeconomic situation, Koch et al. (2014) selected the economic prosperity index as a macroeconomic factor to add to the model. The results of the two researchers both showed that the carbon emission price is significantly affected by macroeconomic factors. Regarding the impact of market policy mechanisms, Xu \& Deng (2016) studied the impact of the financial option system on the spot transaction price of carbon emissions, and believed that the financial option system will reduce the risk of carbon price fluctuations. Regarding the impact of information disclosure, Conrad, Waldemar, \& Rotful (2012) analyzed the impact of the release of three different types of information on the EU market carbon emission price. The three types of published information are national distribution plans, information on the status of economic development, and information on future economic prospects. It is found that a loose national allocation plan will increase the supply of the carbon emission market, leading to a price drop, and the effect will last for a long time. The current economic development status and expectations of future economic prospects will also have a significant impact on carbon emission prices.

The literatures on the volatility factors of EU carbon trading prices provide important references for studying the issue of carbon emission price volatility in China. Because the carbon emission allowance trading price fluctuations will be affected by some common factors, such as energy prices, macroeconomics, and climate change. However, due to differences in the market environment and mechanisms, the price fluctuations of carbon emission allowance trading in China have characteristics different from those in the EU market, such as structural mutations. The current literature cannot give a reasonable explanation for this feature. So this paper captures the characteristics of the mutation of the carbon emission price of China, and conducts research from the factors of market trading mechanism.

\section{Theoretical Analysis}

The mechanism of the carbon trading market is to allocate a certain amount of carbon dioxide emission allowances to emission control companies, allowing emission control companies and other market investors to freely trade carbon emission allowances, thereby guiding the flow of funds to the enterprises that can achieve low-cost emission reductions and generate carbon emission allowance surplus. The purpose is to increase the added value and motivation of enterprises to reduce emissions. As a market transaction subject, the price of carbon emission rights will fluctuate up and down under the influence of internal 
market mechanisms and multiple external factors.

According to the carbon emission allowance trading mechanism, each trading market determines the total amount of carbon emission allowances at the beginning of each year's contract and allocates the corresponding allowances to the emission control companies. The emission control companies need to complete the allowance payment according to the allocated allowances before the performance of the contract. The performance date of the trading pilot is concentrated in May to July of each year. When a new contract period is entered, the total amount of allowances and the allocation plan will directly determine the market supply and demand, and then determine the initial price of the transaction, which may cause discontinuous changes in the prices of the two contract periods before and after. In addition, through the observation of market transactions, affected by the performance settlement requirements, the market transaction volume will increase sharply during the upcoming period of the performance day each year, and it will quickly fall after the performance day. Severe fluctuations in trading volume may cause non-linear sudden changes in prices. Based on the above analysis, driven by the market mechanism, the carbon trading price is highly likely to jump or change during a period of time when the two contract cycles converge.

\section{Empirical Test}

The empirical research on the structural mutation of carbon emission price in this paper includes two levels: Firstly, the Bai-Perron multiple endogenous mutation point test is carried out on the price sequence. And secondly, a more in-depth analysis and judgment is carried out in combination with the time point and direction of the price mutation. This paper takes Beijing, Tianjin, Shanghai, Hubei, Chongqing, Guangdong and Shenzhen carbon emission allowance trading pilots as the research objects, and establishes sample data for each pilot and conducts empirical testing.

\subsection{Data Source}

The daily closing price of each trading pilot from the date of trading start to December 31, 2020 is selected as the trading price sample of each pilot, and the data comes from the China Carbon emission allowance trading Network. In order to more accurately reflect the real market supply and demand, it is necessary to remove the data on the trading day without transactions, and record the carbon emission price on the $t$ day as $C P_{t}$. The sample numbers of Beijing, Tianjin, Shanghai, Hubei, Chongqing, Guangdong and Shenzhen pilots are 1075, 662, $1036,1596,553,1424$, and 1647 respectively.

\subsection{Descriptive Statistical Analysis}

In order to have a basic understanding of the carbon emission allowance trading price of each pilot, a descriptive statistical analysis is carried out, as shown in 
Table 1. On the whole, the statistical distribution characteristics of prices showed large differences among the pilots. From the perspective of the average price: the average prices of the pilots in Beijing, Shanghai, and Shenzhen are relatively high. This is because the three pilots are established earlier, covered more industries and included companies, and the level of financial market development are relatively high. The market demands for carbon emission trading are relatively high, which pushes up the trading price of carbon emission. From the span of the maximum and minimum carbon emission prices and the size of the standard deviation, it can be concluded that the price fluctuations in the Shenzhen and Beijing pilots are relatively large. From the perspective of skewness, all pilots' price distributions have obvious right-skewed characteristics, indicating that there are more values in these markets where the price distribution are below the average price. From the view of kurtosis value, the high kurtosis coefficient of Guangdong and Tianjin market prices indicates that the two markets have a high degree of price concentration; the kurtosis of Beijing and Chongqing are below 3, indicating that the price concentration of these two markets is not concentrated.

\subsection{Empirical Test}

Based on the theoretical analysis that the market compliance mechanism may cause non-linear mutations in carbon emission prices, $\mathrm{H} 1$ is proposed: the carbon emission allowance trading price will undergo structural mutations before and after the compliance date each year. In order to verify this conjecture, this section conducts structural mutation test on the time series of carbon valence, and judges whether $\mathrm{H} 1$ is valid according to the time point of the mutation.

\subsubsection{Bai-Perron Structural Mutation Points Test}

The Bai-Perron multiple endogenous structural mutation points test method proposed by Bai and Perron not only overcomes the problem of the exogenous setting of structural mutation points, but also can directly observe multiple mutation time points in time series data (Bai \& Perron, 2003).

Table 1. Descriptive statistics of transaction prices of the seven pilot projects.

\begin{tabular}{cccccccc}
\hline Pilot & Mean & Median & Maximum & Minimum & $\begin{array}{c}\text { Standard } \\
\text { Deviation }\end{array}$ & Skewness & Kurtosis \\
\hline Beijing & 59.86 & 53.15 & 102.96 & 30.00 & 16.0440 & 0.8090 & 2.5562 \\
Tianjin & 24.06 & 24.45 & 50.10 & 7.00 & 6.0175 & 0.5134 & 5.0963 \\
Shanghai & 32.42 & 35.73 & 49.50 & 4.20 & 10.3860 & 1.3426 & 3.9432 \\
Hubei & 23.32 & 24.27 & 53.85 & 10.07 & 6.5393 & 0.3480 & 3.3434 \\
Chongqing & 12.69 & 7.95 & 47.52 & 1.00 & 11.1409 & 1.0173 & 2.9777 \\
Guangdong & 21.94 & 17.82 & 77.00 & 8.10 & 12.0391 & 2.2959 & 8.7196 \\
Shenzhen & 37.35 & 34.50 & 143.99 & 3.03 & 19.9956 & 0.9393 & 4.2351 \\
\hline
\end{tabular}

Source: Calculated based on the price data of Carbon emission allowance trading Network. 
The Bai-Perron multiple endogenous structural mutation points test is performed on time series data, and an autoregressive model is generally established, in which the order of the lag term is determined by AIC and SC criteria. Then select multiple endogenous mutation tests by EViews 10 and output structural mutation points of the time series to be tested. Table 2 shows the number of price mutation points and the time points of the price mutations in each pilot.

From the results, we can draw the following conclusions: Firstly, there have been several structural mutations in the price of each carbon emission allowance trading pilot. Secondly, most of the mutations occurred around the compliance date, which is between May and July each year.

\subsubsection{Analysis of Reasons for Price Mutation}

The results verify that the compliance mechanism is the factor that causes the structural mutation of the carbon emission allowance trading price. The surge in the volume of carbon allowance transactions within a period of time before the annual compliance date constitutes the direct cause of the price mutation. The deeper reason lies in three aspects: Firstly, the emission control companies lack active management and trading enthusiasm for carbon allowances. The main purpose of participating in carbon emission allowance trading is to complete the compliance requirements. So the trading of carbon allowances is centralized before the compliance date, which leads to sudden and large changes in market prices. After entering a new contract cycle after the end of each year's performance date, the activity of market trading drops to a low level, which also leads to drastic changes in prices. Secondly, the investment attributes of carbon allowances have not been fully explored, and the participation of market investors is low. It is understandable that the control companies' main trading purpose is to fulfill the demand, but the problem is that the daily trading activities for investment purposes are too low, and the participation of other market investors except for the control companies is insufficient. Among the seven pilot carbon trading markets in 2020, the Guangdong market has the highest carbon quota

Table 2. The number of sudden changes in the transaction price structure of the seven pilot projects and the timing of the sudden changes.

\begin{tabular}{ccccccc}
\hline Pilot & $\begin{array}{c}\text { Number of price } \\
\text { mutations }\end{array}$ & $\begin{array}{c}\text { Mutation } \\
\text { point 1 }\end{array}$ & $\begin{array}{c}\text { Mutation } \\
\text { point 2 }\end{array}$ & $\begin{array}{c}\text { Mutation } \\
\text { point 3 }\end{array}$ & $\begin{array}{c}\text { Mutation } \\
\text { point 4 }\end{array}$ & $\begin{array}{c}\text { Mutation } \\
\text { point 5 }\end{array}$ \\
\hline Beijing & 4 & $2015 / 5 / 19$ & $2016 / 4 / 25$ & $2019 / 3 / 28$ & $2020 / 6 / 18$ & \\
Tianjin & 5 & $2014 / 6 / 24$ & $2015 / 5 / 13$ & $2016 / 6 / 22$ & $2018 / 6 / 20$ & $2020 / 5 / 19$ \\
Shanghai & 5 & $2015 / 6 / 1$ & $2017 / 7 / 24$ & $2018 / 6 / 1$ & $2018 / 8 / 22$ & $2019 / 8 / 2$ \\
Hubei & 5 & $2015 / 3 / 6$ & $2016 / 4 / 26$ & $2017 / 6 / 22$ & $2018 / 7 / 26$ & $2020 / 7 / 3$ \\
Chongqing & 4 & $2015 / 6 / 26$ & $2016 / 8 / 31$ & $2018 / 5 / 30$ & $2020 / 6 / 23$ & \\
Guangdong & 5 & $2014 / 7 / 8$ & $2015 / 5 / 22$ & $2016 / 6 / 06$ & $2017 / 5 / 31$ & $2019 / 8 / 29$ \\
Shenzhen & 5 & $2014 / 6 / 29$ & $2016 / 7 / 18$ & $2018 / 6 / 25$ & $2019 / 4 / 8$ & $2020 / 4 / 28$ \\
\hline
\end{tabular}

Source: Model output result. 

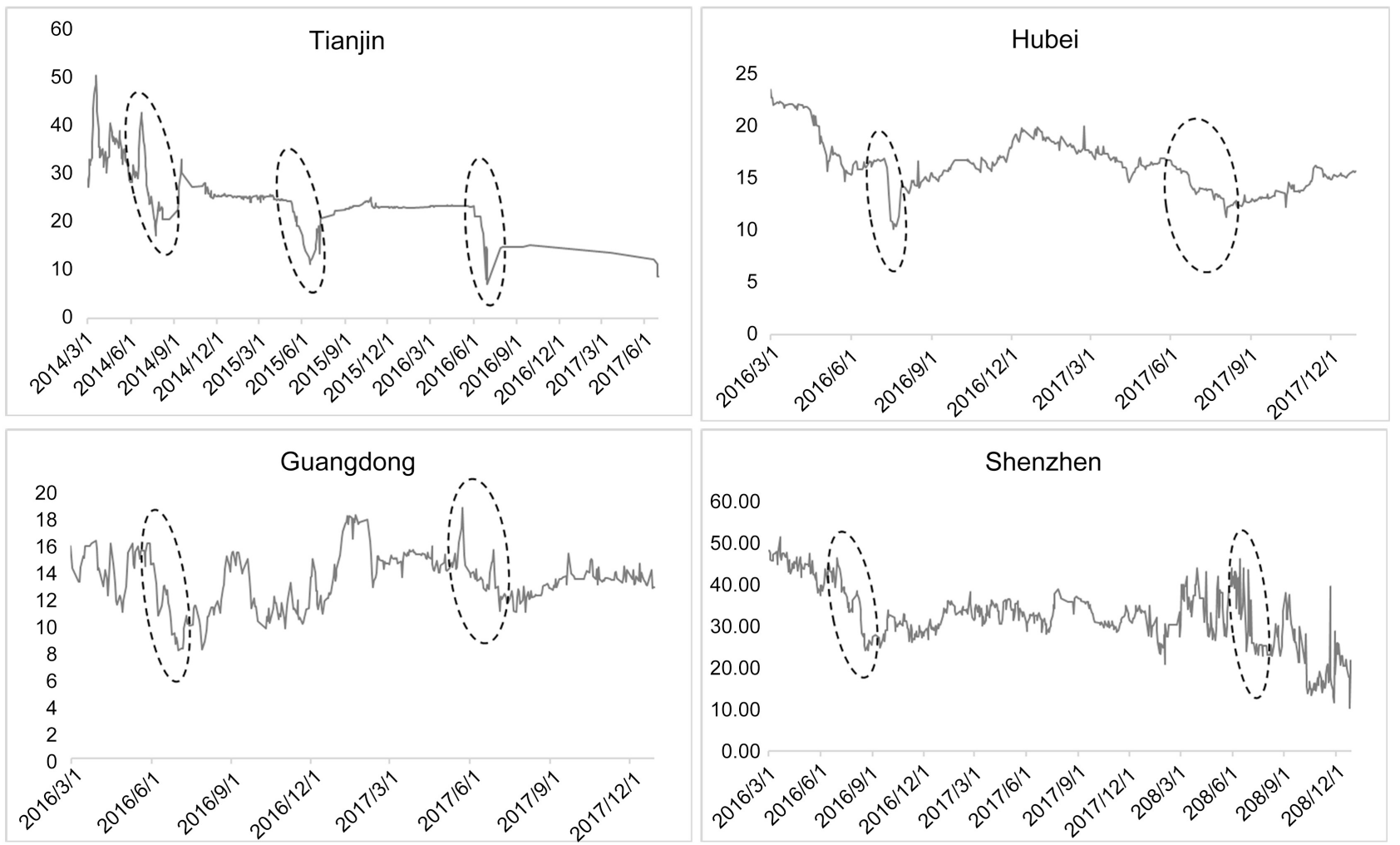

Figure 1. The downward trend of price of some pilots before the compliance period. Source: Carbon emission allowance trading Network. 
sion price fluctuations, and finds that there are multiple structural mutations in the carbon emission price of each pilot, and the mutation point occurs around the annual compliance date, combined with the surge in market transaction volume before the annual compliance date. Circumstances, it is believed that the market compliance mechanism is the direct internal factor that causes the sudden change of the carbon emission price. There are also some possible deep-seated reasons such as the poor active management capabilities and trading enthusiasm of emission control companies for carbon allowances, the low participation of investors in other markets, the weak investment values of carbon allowances, and the excessive total supply of allowances. Based on the above conclusions and the problems reflected, the following suggestions are made for the further improvement of China's carbon emission allowance trading market:

Firstly, the construction of market mechanisms should be improved and more market participants need be included. To truly play the role of the national carbon trading market in reducing emissions, it must be scientific and reasonable in the formulation and allocation of allowances, which is directly related to the formation of transaction demand and transaction prices. In order to enhance market trading power and strive to achieve the goal of "dual carbon", it is recommended to tighten the total amount of allowances year by year, and gradually increase the proportion of auction allocation to better play the role of market competition mechanism. Furthermore, the national market can incorporate a wider range of industries and enterprises, and introduce more qualified institutions and individual investors to enhance market liquidity and trading vitality. Of course, while introducing more investors, it is also necessary to strengthen supervision and various institutional guarantees to prevent greater market risks caused by excessive speculation.

Secondly, enterprises that control emissions should accelerate their green transformation and improve their ability to actively manage carbon allowances. With the ever-tightening of the total allocation of carbon allowances in the future, emission control companies themselves must accelerate the transformation of green and clean production, reduce their dependence on fossil energy, strengthen the research and development of emission reduction technologies, and reduce carbon dioxide and other greenhouse gas emissions. In addition, in order to prevent excessive price fluctuations due to excessive concentration of market transactions before the date of compliance, companies participating in emission control should strengthen active management of carbon allowances, raise awareness of the financial asset attributes of carbon emission rights, strengthen professional training for relevant practitioners and analyze the carbon allowance asset trading strategies. Relevant regulatory authorities should also give appropriate guidance to alleviate the issue of transactions driven by contract performance and make the market run more smoothly and healthily.

Thirdly, financial institutions should take the initiative to carry out carbon finance business and promote reasonable pricing in the market. Carbon emis- 
sion rights naturally have the attributes of financial assets. The prerequisite for enhancing investment value of carbon emission allowances is to activate market liquidity and promote reasonable market pricing. This is both an opportunity and an inescapable mission for financial institutions. Therefore, financial institutions should proactively explore carbon finance business, which can be carried out from two aspects: one is to improve the professional investment ability of participating in the carbon trading market, actively participate in the carbon trading, stimulate market vitality, and promote the improvement of the market pricing mechanism. Improve quantitative investment capabilities, be familiar with trading rules and market mechanisms, and improve the value and risk management of investment portfolios. The second is to explore carbon asset management business in the public and private sectors. For corporate customers, financial institutions can provide carbon allowance management and carbon asset financial advisory services for companies that are included in the carbon trading market to control emissions, to help companies take the initiative to carry out carbon trading business and revitalize their carbon allowance assets. For individual customers, some carbon fund wealth management products can be developed to helps retail investors conduct more professional investment management, which can not only reduce market risks, but also further activate the liquidity of the carbon trading market.

\section{Conflicts of Interest}

The author declares no conflicts of interest regarding the publication of this paper.

\section{References}

Aatola, P., Ollikainen, M., \& Toppinen, A. (2013). Price Determination in the EUETS Market: Theory and Econometric Analysis with Market Fundamentals. Energy Economics, 36, 380-395. https://doi.org/10.1016/j.eneco.2012.09.009

Bai, J., \& Perron, P. (2003). Computation and Analysis of Multiple Structural Change Models. Journal of Applied Econometrics, 18, 1-22. https://doi.org/10.1002/jae.659

Conrad, C., Rittler, D., \& Rotful, W. (2012). Modeling and Explaining the Dynamics of European Union Allowance Prices at High-Frequency. Energy Economics, 34, 316-326. https://doi.org/10.1016/j.eneco.2011.02.011

Hintermann, B. (2012). Allowance Price Drivers in the First Phase of the EUETS. Journal of Environmental Economics and Management, 59, 43-56. https://doi.org/10.1016/j.jeem.2009.07.002

Keppler, J. H., \& Bataller, M. M. (2010). Causalities between $\mathrm{CO}_{2}$, Electricity, and Other Energy Variables during Phase I and Phase II of the EUETS. Energy Policy, 38, 3329-3341. https://doi.org/10.1016/j.enpol.2010.02.004

Koch, N., Fuss, S., Grosjean, G., \& Edenhofer, O. (2014). Causes of the EUETS Price Drop: Recession, CDM, Renewable Policies or a Bit of Everything?-New Evidence. Energy Policy, 73, 676-685. https://doi.org/10.1016/j.enpol.2014.06.024

Nwani, C. (2017). Causal Relationship between Crude Oil Price, Energy Consumption 
and Carbon Dioxide $\left(\mathrm{CO}_{2}\right)$ Emissions in Ecuador. OPEC Energy Review, 41, 201-225. https://doi.org/10.1111/opec.12102

Xu, L., \& Deng, S. J. (2016). Thomas Valerie M. Carbon Emission Permeit Price Volatility Reduction through Financial Options. Energy Economics, 53, 248-260.

https://doi.org/10.1016/j.eneco.2014.06.001 